\title{
(2) Evaluation of Sweet Potato (Ipomea batata I.) aße Varieties for Total Storage Root Yield in South and South East Zones of Tigray, Ethiopia
}

\author{
Birhanu Amare ${ }^{1 *}$, Fetien Abay ${ }^{2}$, Yemane Tsehaye ${ }^{3}$
}

${ }^{1}$ Alamata Agricultural Research Center, Alamata, Tigray, Ethiopia

${ }^{2,3}$ Mekelle University, Mekelle, Tigray, Ethiopia

*E-mail for correspondence: birhaamg@gmail.com

Cell Phone: +2510913441230

Received: Aug 10, 2014;

Accepted: Aug 22, 2014;

Published: Aug 31, 2014

Source of Support: Nil

Conflict of Interest: None Declared

\begin{abstract}
Seven sweet potato varieties (Bellela, Kabode, Kulfo, LO, Temesgen, Tulla and Vitae) were tested in southern and eastern zones of Tigra, Ethiopiay in 2012 to evaluate their total root yield potential. Randomized complete block design with three replications was used for the experiment Yield data was analyzed using combined ordinary analysis of variance and the additive main effect and multiplication interaction effect model (AMMI). The combined analysis of variance across locations showed significant variation among genotypes, locations and the genotypes by locations interaction for the total storage root yield ( $\mathrm{t} / \mathrm{ha}$ ). Based on this, the superior mean total root yield (26.82 $\mathrm{t} / \mathrm{ha}$ ) was obtained at Kukufto testing location while the inferior $(13.45 \mathrm{t} / \mathrm{ha}$ ) was at Rarhe. Similarly, among the genotypes, LO gave the highest mean total root yield (30.9 $\mathrm{t} / \mathrm{ha}$ ), while bellela gave the lowest $(7.78 \mathrm{t} / \mathrm{ha})$. The AMMI analysis for the total storage root yield also showed highly significant difference for genotypes, locations and the genotypes by locations interaction components The contribution of genotype, location and genotype by location interaction to the total variation in root yield was about $54.1 \%, 21.4 \%$ and $19.4 \%$, respectively. The genotype main effect contributed more to the total variability indicating that the variation was largely due to the inheritance of genotype effect. The genotype by location interaction was further partitioned using AMMI model and the first two principal components explained $100 \%$ of the total variability. The model captured $83.4 \%$ of the interaction sum of squares with the first Interaction Principle Component Axis (IPCA) (in $58.3 \%$ of the interaction degrees of freedom) and $16.6 \%$ by the second IPCA axis (with $41.7 \%$ of the G x E d.f). AMMI biplot view of this study identified kukufto as best testing location and LO, Tulla and Kulfo as best genotypes for south and south east zones of Tigray region.
\end{abstract}

Keywords: Genotype by Location Interaction (GLI), Location, Sweet potato, Varieties (Genotypes)

\section{INTRODUCTION}

Sweet potato is grown around the world in diverse environments, often by small farmers in marginal soils, using few inputs (Manrique and Hermann, 2000). Likewise, this crop is one of the root and tuber crops grown in Ethiopia, and it is the third important root crop next to Enset and Potato (Engida et al., 2009). The area covered and production of sweet potato in Ethiopia increases from time to time. However, not only the sweet potato research but also its production is very limited to specific regions, like that of South Nation Nationalities and Peoples, Oromia, Harerghe and Amhara regions. In Tigray region, sweet potato is grown mainly in the lowlands and medium altitude areas. Currently, the area coverage of the crop in the region is increasing from time to time. Despite the crop potential, lack of improved sweet potato varieties suitable for different agro-ecologies and resistant to insect pests are some of the factors that hider the crop expansion.

Sabaghnia et al. (2006) pointed out the importance of studying genotype by location interaction not only from the genetic and environmental point of view but also its relevance to the production problems of agriculture in general. The importance of any variety testing program is to obtain the most accurate estimate of variety performance that is possible within the limitations imposed by the environmental growing conditions (Addis, 2003). Farmers are basically interested in superior and specifically adapted varieties to their condition and with a high degree of stability over time (Scott and Maldonando,1998). Hence, the study of multi-location variety trial is particularly relevant to countries that have diverse agro-ecologies, as is the case in Ethiopia. 
The well performing ability of sweet potato over wide range of environments is of major interest to plant breeders (Moussa et al., 2011). Due to the higher productivity and drought tolerance of the crop, it can play vital role in achieving food self sufficiency of the region. Even though Tigray region has wider agro-ecological zones and suitable for sweet potato production, unavailability of improved sweet potato varieties that can give high yield and tolerance for diseases and insect pests is a major problem in most sweet potato growing areas of Tigray. Moreover, despite of the diverse agro-ecologies of the Tigray region, multi-location trials have not been conducted for sweet potato varieties and/or genotypes.

A more recent development in measuring genotype adaptability over locations is the application of a multiplicative interaction models such as Additive Main Effects and Multiplicative Interaction (Gauch and Zobel, 1996). AMMI analysis permits estimation of interaction effect of a genotype in each location and it helps to identify genotypes best suited for specific locations (Das et al., 2010; Misra et al., 2009; Gauch and Zobel, 1988). AMMI combines the analysis of variance of genotypes and the location main effects with principal component analysis of the G x L into a unified approach (Gauch and Zobel, 1996). It uses ordinary ANOVA to analyse the main effects (additive part) and Principal Component Analysis (PCA) to analyse the non additive residual left over by the ANOVA. The results can be graphically represented in an easily interpretable and informative biplot that shows both main effects and $G \times \mathrm{L}$ interaction. The objective of the study was to evaluate the yield performance of the sweet potato genotypes across different locations of the Tigray region.

\section{Materials ANd Methods}

The experiment was carried out in three locations of Southern and South Eastern zones of Tigray region. These locations were Illala, Kukufto and Rarhe and the materials used in this trial were Bellela, Kabode, Kulfo, LO, Temesgen, Tulla and Vitae. The experiment was arranged in Randomized Complete Block Design (RCBD) with three replications and the materials were planted under rainfed condition in the 2012. Plot size of 2.4 meter by 4.2 meter with a respective inters-and intra row spacing of 0.60 and $0.30 \mathrm{~m}$ were used. The Net harvestable plot was $2.4 \mathrm{~m} \times 3 \mathrm{~m}$ $\left(7.2 \mathrm{~m}^{2}\right)$. Total storage root yield data was taken during the study and the central five rows were harvested from each plot leaving border rows to avoid border effects.

Statistical Analysis: Combined analysis of variance (ANOVA) for yield and yield component characters of the varieties tested across locations was performed using the GenStat (Payne et al., 2007) statistical package. Before running data analysis, the data were first tested for normality with Shapiro Wilk test method. Accordingly, all data set showed normal distribution. The pooled ANOVA was used to evaluate the presence of genotype by location interaction and to partition the variation due to variety, location and genotype by location interaction.
Since the pooled analysis of variance considers only the main effects, the additive main effect and multiplicative interaction model (AMMI) was computed. The AMMI method used the standard ANOVA procedure, where after, the AMMI model separates the additive variance from the multiplicative variance (interaction), and then used Interaction Principal Component Analysis (IPCA) to explain the pattern in the genotype by location and residual matrix and also to extract a new set of coordinate axes (Royston, 1995). The AMMI model is expressed as the following model for the observation Yij on Genotype $i$ in Environment j:

$Y_{i j}=\mu+G_{i}+E_{j}+\sum \lambda_{k} \alpha_{i k} \gamma_{j k}+\varepsilon_{i j} \quad$ where,

$Y i j$ is the observed mean yield of the ith genotype in the jth environment,

$\mu$ is the general (Grand) mean)

$G i$ and $E j$ represent the effects of the genotype and environment respectively,

$\lambda k$ is the singular value of the $k$ th axis in the principal component analysis,

aik is the eigenvector of the $i$ th genotype for the $k$ th axis,

$\gamma j k$ is the eigenvector of the $j$ th environment for the $k$ th

axis, $n$ is the number of principal components in the model, and

$\varepsilon_{\mathrm{ij}}$ is the average of the corresponding random errors.

Based on the results obtained from combined ANOVA, adaptability analysis for sweet potato varieties and traits was determined by AMMI model using GenStat (Payne et al., 2007). In addition, Environment mean, Environment index and AMMI Stability Value (ASV) were also used to determine the genotype adaptability in the location

\section{RESULT AND Discussion}

\section{Analysis of Total Storage Root Yield Using AMMI Model}

The analysis of variance of AMMI model for total storage root yield (Table 1$)$ showed significant differences $(P<$ 0.01 ) for genotype and location main effects, as well as for genotype by location interaction. Genotype main effect contributed more to the total variability of total root yield than does the location. Similar results were observed by Faliconer (1981) and Tumwegamire (2011) in the GEI of sweet potato trials made by AMMI model. All these researchers found significant $G \times L$ interaction for yield and stressed the usefulness of AMMI analysis for selection of genotypes in a location.

Following the AMMI model, a principal component analysis (PCA) was carried out to decompose the $\mathrm{G} \times \mathrm{L}$ interaction for root yield. The partitioning of variance components indicated that contribution of location was $21.4 \%$ of the total variation, $54.1 \%$ due to genotype, and $19.4 \%$ due to GLI (Table 1). The higher proportion of variance due to genotype more than location indicates that location effects on total storage root yield was not large. Another study conducted by Zenebe and Hussien (2009) on sesame crop indicated that the genotype main effect had contributed more than the location. The 
genotypes were differently influenced by location, which hinder the recommendation of genotype for the whole area embraced by the study (Lavoranti et al., 2007). It is therefore necessary to conduct a detailed study of that interaction. In this study, the AMMI analysis partitioned the sum of squares of genotype by location interaction (GLI) into two interaction principal components axes (IPCA), of which, both IPCA showed significant difference. According to Steven (2008), a next IPCA that offers little increase in the total variance explained is a criterion to include how many PCA to use. Hence, a third IPCA is not necessary in this study due to its little importance in the explaining of the variance.

Table 1: Analysis of variance for Additive Main effects and Multiplicative Interaction (AMMI) of total storage root yield ( $\mathrm{t} / \mathrm{ha}$ ) for 7 varieties and in 3 locations

\begin{tabular}{|l|c|c|c|c|}
\hline Source & DF & SS & MS & $\begin{array}{c}\text { \% SS } \\
\text { explained }\end{array}$ \\
\hline Rep within Loc. & 6 & 75 & 12.5 & 0.7 \\
\hline Genotype (G) & 6 & 5529 & $921.5^{* *}$ & 54.1 \\
\hline Location(L) & 2 & 2188 & $1094.2^{* *}$ & 21.4 \\
\hline Gx L Interaction & 12 & 1987 & $165.6^{* *}$ & 19.4 \\
\hline IPCA 1 & 7 & 1658 & $236.9^{* *}$ & 83.4 \\
\hline IPCA 2 & 5 & 329 & $65.7^{* *}$ & 16.6 \\
\hline IPCA Residuals & 0 & 0 & 0 & 0 \\
\hline Error & 36 & 440 & 12.2 & \\
\hline Total & 62 & 1021.9 & 164.8 & \\
\hline
\end{tabular}

Grand mean $=18.56 \quad R$-squared $=0.95 ; C . V=19.3 \% ; * *$

Highly significant at 0.01 probability level

As exhibited in Table 1 , the AMMI model contained $94.9 \%$ of the treatment SS (the sum of genotype, location and $G \times L$ interaction sum of squares) and the IPCA residual contained $0 \%$ of the treatment sum of squares which indicates the effectiveness of AMMI in summarizing the data within two IPCA. Hence, it is possible to construct the AMMI bi-plot and computing of the varieties and locations effects.

Result from AMMI model showed that the first interaction principal component axis (IPCA1) captured $83.4 \%$ of the interaction sum of squares with $58.33 \%$ of the corresponding degree of freedom. Similarly, the second interaction principal component axis (IPCA2) explained a further $16.6 \%$ of the variety by location interaction sum of squares in $41.67 \%$ of the interaction degree of freedom. Hence, both IPCA's captured $100 \%$ portion of the variability leaving $0 \%$ residual. The more contribution explained by the first interaction principal component axis (IPCA 1) showed more importance in describing the variety by location interaction than the second principal component axis (IPCA 2). There is a decreasing contribution to the $G \times L$ sum of squares with an increasing number of IPCAs (Abamu and Alluri, 1998). The same trend was observed in the present study of total storage root yield for different sweet potato varieties. Another authors (Zobel et al., 1988; Solomon et al., 2008; Ilker et al., 2009) also reported that the first two interaction principal component axes best explain the interaction sum of squares in different trials.

The significant scores of IPCA (in absolute values) indicate the contribution of each variety to the interaction variance explained by that specific axis. Hence, the greater the IPCA score, the more response to the interaction effect and the more specifically adapted a genotype is to a certain location (Hassanpanah, 2010). The reverse is true for wider adapted variety that has lower interaction (lower IPCA scores). Therefore, based on the IPCA1, variety Kulfo (2.331) had largest contribution followed by Bellela (-2.196) and Tulla (2.124) to the interaction variance among other varieties. On the contrary, genotype Kabode maintained the least contribution to the interaction effect followed by $\mathrm{LO}$ and Temesgen. According to location IPCA 1 scores, Illala had lower G x L interaction (-0.761), whereas the highest IPCA 1 scores belonged to Kukufto followed by Rarhe (Table 3). Due to its highest IPCA 1 scores, Kukufto had contributed largely to GLI and this was high yielding location.

As reported by Mohammedi et al. (2007) and indicated by their small IPCA 1, non-adapted genotypes yielded low at all locations. Moreover, Hintsa (2012) stated that genotypes that had IPCA 1 scores $>0$ were identified as higher yielding and those that had IPCA 1 Scores $<0$ were identified as lower yielding. Based on this, LO, Tulla and Kulfo varieties had high and positive IPCA 1 scores and above average yield (Table 2; Figure 1). Therefore, these varieties are characterized by specific adaptation to the favorable location (Kukufto). Whereas, Bellela, Temesgen and Vitae varieties had high negative magnitude of IPCA 1 scores but below average storage root yield.

Table 2: Mean total storage root yield (t/ha) and IPCA scores of Genotypes and locations

\begin{tabular}{|c|c|c|c|c|c|c|c|c|c|c|c|}
\hline \multirow{3}{*}{$\begin{array}{l}\text { Geno } \\
\text { Code }\end{array}$} & \multirow{3}{*}{$\begin{array}{l}\text { Genotypes } \\
\text { Name }\end{array}$} & \multicolumn{6}{|c|}{ Locations } & \multirow{3}{*}{$\begin{array}{l}\text { Variety } \\
\text { Mean }\end{array}$} & \multirow{3}{*}{ Rank } & \multirow{3}{*}{$\begin{array}{l}\text { IPCA1 } \\
\text { Score }\end{array}$} & \multirow{3}{*}{$\begin{array}{l}\text { IPCA2 } \\
\text { Score }\end{array}$} \\
\hline & & \multicolumn{2}{|c|}{\begin{tabular}{|l|} 
Rarhe \\
\end{tabular}} & \multicolumn{2}{|c|}{ Kukufto } & \multicolumn{2}{|c|}{ Illala } & & & & \\
\hline & & Mean & Rank & Mean & Rank & Mean & Rank & & & & \\
\hline 5 & Bellela & 4.92 & 7 & 5.69 & 7 & 12.73 & 4 & 7.78 & 7 & -2.196 & -2.479 \\
\hline 6 & Kabode & 5.43 & 6 & 18.83 & 4 & 7.00 & 6 & 10.42 & 5 & 0.017 & 0.098 \\
\hline 3 & Kulfo & 13.71 & 4 & 43.49 & 3 & 24.44 & 3 & 27.21 & 3 & 2.331 & -0.828 \\
\hline 7 & LO & 22.96 & 1 & 45.01 & 2 & 24.72 & 1 & 30.9 & 1 & 1.389 & 0.759 \\
\hline 4 & Temesgen & 12.20 & 5 & 13.65 & 6 & 5.30 & 7 & 10.38 & 6 & -1.611 & 1.220 \\
\hline 2 & Tulla & 17.87 & 2 & 45.55 & 1 & 24.63 & 2 & 29.35 & 2 & 2.124 & -0.019 \\
\hline 1 & Vitae & 17.09 & 3 & 15.53 & 5 & 9.08 & 5 & 13.9 & 4 & -2.055 & 1.249 \\
\hline Locati & Mean & 13.45 & & 26.82 & & 15.41 & & 18.56 & & & \\
\hline
\end{tabular}

This signifies their specific adaptation to low yielding locations. On the other hand, the variety Kabode had nearly zero IPCA 1 score that indicates its wider adaptability. Therefore, however the overall mean yield of Kabode remained below average, its IPCA 1 (0.017) score approximated near to zero and thus, its adaptability was wider across locations as compared to other varieties. According to the AMMI analysis method, almost all varieties except Kabode and LO had showed more specific adaptability to the tested locations. But the degree of specificity (positive or negative) was higher to the varieties that exhibited more IPCA 1 scores. The negative IPCA 1 scored varieties gave below average storage root yield in the low yielding locations (Hintsa, 2012). 
The AMMI 1 biplot of the total storage root yield of the genotypes grown in three locations was demonstrated in Figure 1. In this bi-plot, the IPCA 1 scores of genotypes and locations are plotted against their respective means, where the abscissa shows the main effects while the ordinate shows the first IPCA. The main effects (Genotype \& Location) accounted for $75.5 \%$ and IPCA1 accounted for $16.18 \%$ and so the AMMI I bi-plot gave a model fit of $91.68 \%$, which allowed us to interpret the main and interaction effects.

Varieties such as LO, Tulla and Kulfo had high IPCA 1 scores (positive direction) and mean yield (30.9, 29.35 and $27.21 \mathrm{t} / \mathrm{ha}$, respectively) and performed well in the high yielding location, Kukufto (Table 2; Figure 1). The variety LO was overall the best yielding variety with average yield of $30.9 \mathrm{t} / \mathrm{ha}$. On the other hand, Bellella and Vitae showed similar interaction but Kabode and Temesgen exhibited similar mean yield. The similarity of Bellela and vitae in the IPCA 1 scores and their difference in mean total root yield indicated the variation existed in the main effects. On the other hand, Kabode and Temesgen had similar total root yield but different in IPCA 1 scores. This showed that varieties interacted with locations differently. Bellela and Kulfo as well as Temesgen and LO with their difference in total root yield and significant variation in the scores of IPCA 1 were indicated to differ in both main and interaction effects (Table 2). The other genotypes have shown wider variability among themselves.

Varieties such as LO, Tulla and Kulfo had a positive and high IPCA 1 score as well as mean yield and had a better performance at Kukufto location (a high yielding with high IPCA 1 score). As indicated by Zobel et al. (1998), this type of interaction, where genotypes and testing locations have a similar sign and magnitude of IPCA's, it implies a positive association. .Generally, genotype LO was the overall winner and top rank but Bellela was the lowest performing genotype across the locations.

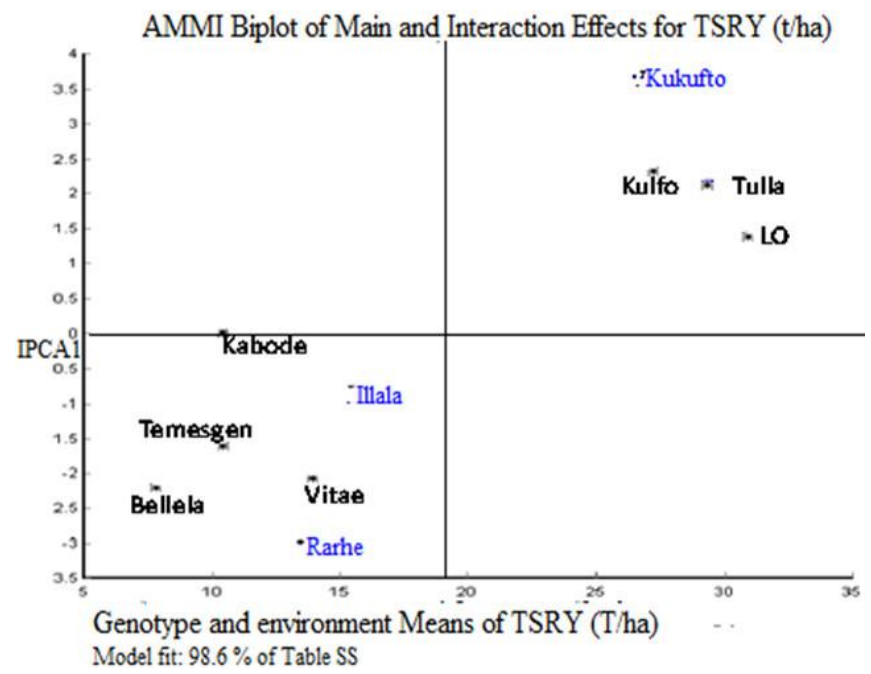

Figure 1: AMMI 1 bi-plot of total storage root yield of sweet potato genotype in three locations.
Note: TSRY Total Storage Root Yield and, the vertical line in the center of AMMI 1 represents the general mean of $18.56 \mathrm{tha}^{-1}$

In view of locations, Rarhe and Illala relatively showed similar mean total storage root yield but shown differences in their interaction pattern with varieties. In terms of yielding performance, Kukufto was the highest yielding location but Rarhe and Illala gave below average main effect and thus, they are lower yielding locations. However, individual location scored higher and above average root yields for LO, Tulla and Kulfo varieties. The average total storage root yield at the individual locations ranged from 13.45 t/ ha at Rarhe to 26.82 t/ha at Kukufto (Table 3). This difference could be due to their wide range of environmental conditions resulting from varying amounts of temperature, soil fertility, moisture and other factors.

According to Soares de Vasconcelos et al. (2011), an environment is classified as unfavorable if the difference of environmental index is negative and favorable if the difference is positive as environmental index is the difference between the mean of each environment and the overall mean of the experiment (Table 3). Therefore, location Kukufto, with its environmental index value of 8.26, was the most suitable location for realizing root yield potential of varieties. On the other hand, Rarhe recorded the least environmental index of -5.11 and hence, the least favorable environment as compared with others. Similar result was reported by Zenebe and Hussien (2009) in sesame crop.

Table 3: Location mean, Environment index, ASV and IPCA scores of total storage root yield ( $t / h a)$ across three locations

\begin{tabular}{|c|c|c|c|c|c|}
\hline No & Location & $\begin{array}{c}\text { Environment } \\
\text { mean }\end{array}$ & $\begin{array}{c}\text { Environment } \\
\text { Index }\end{array}$ & ASV & IPCA 1 \\
\hline 1 & Rarhe & 13.45 & -5.11 & 15.14 & -2.984 \\
\hline 2 & Kukufto & 26.82 & 8.26 & 18.89 & 3.745 \\
\hline 3 & Illala & 15.41 & -3.15 & 4.63 & -0.761 \\
\hline
\end{tabular}

In addition to the environment mean, environment Index and IPCA, some researchers such as, Hintsa (2012 and Marlize (2010) were also used the AMMI Stability value (ASV) to determine genotype and location adaptability. In view of that, location and/or genotype that have highest AS V are considered as more responsive to the GLI and are specific adapted. Hence, Kukufto with its highest ASV had showed specific adaptation (Table 3) which supported the analysis made by the IPCA and environment index.

\section{CONCLUSION}

The combined analysis of variance of total root yield $(\mathrm{t} / \mathrm{ha})$ indicated that there was highly significant $(\mathrm{p}<$ 0.01 ) difference among genotypes, locations and genotype by location interaction. Most of the total sum of squares in total root yield was explained by genotype (54.1\%) than location and the interaction. The presence of significant genotype by location interaction effect showed that some genotypes adapted to wider locations, whereas others to specific locations. Based on this, genotype Kabode has 
shown less $\mathrm{G} \times \mathrm{L}$ interaction and it is more adapted in wider locations. Despite of its consistence (wider adaptability), the root yield obtained from this genotype was below average. From the genotypes, LO and Tulla gave highest total root yield per unit area, followed by Kulfo. In this study, Temesgen, Vitae, and Bellela varieties gave below average total root yield and their roots were mostly under sized (less than $100 \mathrm{gm}$ ). To sum up, variety LO scored the highest total root yield, followed by Tulla and Kulfo. On the other hand, bellela gave the lowest total root yield. In view of locations, Kukufto showed highest yield potential and Rarhe the lowest.

\section{ACKNOWLEDGEMENT}

The author thanks Tigray Agricultural Research Institute (TARI), Mekelle University and CIP USAID for their financial support. Thanks are also due to Alamata and Mekelle Agricultural research centers in providing different services during my research study. Moreover, I want to appreciate the agricultural Investors (Ato Solomon Assefa and Ato Gebru Hagos) for their cooperation in their respective experimental sites.

\section{REFERENCES}

Abamu, F.J. and K. Alluri. 1998. AMMI analysis of rainfed lowland rice (Oryza sativa) trials in Nigeria. Plant Breeding 117: 395-397.

Addis Abrha 2003. Genotype by Environment Interaction of Bread wheat Genotypes under Dry Land Growing Conditions of Tigray. Unpublished M.Sc. Thesis, Alemaya University, Alemaya, Ethiopia.

Bondari, K. 1999. Interactions in entomology: Multiple comparisons and statistical interactions in entomological experimentation. Journal of Entomological Science 34: 57-71.

Engida Tsegaye, Mihertu Cherinet, Asfaw Kifle, Daniel Mekonen \& Tesfaye Tadesse 2009. Genotype x Environment Interactions and Yield Stability of Orange Fleshed Sweet potato Varieties Grown in Ethiopia. Tropical Roots and Tubers in a Changing Climate. A Critical Opportunity for the World. 2 -6 Nov 2009 Lima, Peru.

Falconer, D. S. 1981. Introduction to Quantitative Genetics, (2 $\left.{ }^{\text {nd }} \mathrm{ed}\right)$. Longman Group. Limited, New York.

Gauch, H.G. and R.W., Zobel. 1998. Predictive and postdictive success of statistical analyses of yield trials. Theor. Appl. Genet. 76: 1-10.

Hasanpanah, D. 2010. Analysis of Genotype by Environment Interaction by using the Additive Main effects and Multiplicative Interaction in potato cultivars. International journal for plant breeding and Genetics, 4: 23 - 29.

Hintsa Gebru. 2012. Genotype by Location Interaction and Adaptability Study of Bread Wheat (Triticum aestivum L.) genotypes in different wheat growing areas of Tigray region. Unpublished M.Sc. thesis, Mekelle University, Mekelle, Ethiopia.

İlker, E., F. T., Aykut, O. Çaylak, M. Tosun and I. Özmen. 2009. Assessment of Genotype x Environment Interactions For Grain Yield In Maize Hybrids Using AMMI and GGE Biplot Analyses. Turkish J. of Field Crops 14(2): 123 - 135. Turkey.

Lavoranti, O. J., Tadeu dos Santos, C. D., and Wojtek, J. K. (2007). Phenotypic stability via Additive Main effects and
Multiplicative Interaction model with bootstrap resampling. Pesq. Flor. bras., Colombo, n.54, p.45-52, jan./jun..

Manrique, K. and M. Hermann. 2000. Effect of GxE Interaction on Root Yield and Betacarotene Content of Selected Sweetpotato (Ipomoea batatas (L) Lam.) Varieties and Breeding Clones,

Marlize, S. L. 2010. Agronomic performance, consumer acceptability and nutrient content of new sweet potato varieties in South Africa. Unpublished PhD Thesis. South Africa.

Mohammadi, R., M. Armion, A. Shabani and A. Daryaei. 2007. Identification of Stability and Adaptability in Advanced Durum Genotypes Using AMMI Analysis. Asian Journal of Plant Sciences, 6: 1261-126.

Moussa, S. A.M., A. Hala, A. EI-Aal and N. A. EI - Fadi. 2011. Stability study of sweet potato yield and its component characters under different Environments by Joint Regression Analysis., Journal of Horticultural Science and Ornamental plants. 3 (1) pp. 43 - 54. Sadat Branch, Egypt.

Payne, R.W., D. A. Murray, S. A. Harding, D. B. Baird and D. M. Soutar. 1995. GenStat for Windows ${ }^{\circledR}$ (12th Edition) Introduction. VSN International, Hemel Hempstead, UK., 2007.

Sabaghnia, N., H. Dehghani and S. H. Sabaghpour. 2006. Nonparametric methods for interpreting GEI of Lentil genotypes. Crop Sci., 46: 1100-1106.

Scott, G. J., and L. Maldonado. 1998. Sweet potato for the new Millenium: trends in production and utilization in developing countries. CIP program report 1997-1998. CIP, Lima, Peru.

Soares de Vasconcelos, E., M. Silva Reis, C. Damião Cruz, T. Sediyama and C. S. Alberto. 2011. The Integrated method for adaptability \& phenotypic stability analysis. p p. 251257.

Solomon Admassu, Mandefro Nigussie and Habtamu Zelleke. 2008. Genotype $x$ environment interaction and stability analysis for grain yield (Zea mays L.) in Ethiopia. Asian J. Plant Sci., 7 (2): 163169.

Steven, M. H. 2008. Principal Components Analysis (PCA). Department of Geology, University of Georgia, Athens, GA 30602-2501, pp. 3 - 4.

Tumwegamire, S. 2011. Genetic Variation Diversity and Genotype by Environment Interactions of Nutritional Quality traits in East African Sweetpotato. ISBN 978-929060-408-2 .M.Sc. Agric. - Crop Science, B.Sc. Hons Agric. Makerere University, Kampala, Uganda.

Zenebe Mekonen and Hussien Mohammed. 2009. Study on Genotype X Environment Interaction of Oil Content in Sesame (Sesamum Indicum L.). Inaugural Issue: 1(1) pp 36-49.

Zobel, W.R., W. J. Wright and H. G. Gauch. 1998. Statistical analysis of a Yield trial. Agronomy Journal 80: 388-393.

$$
--0 \text {-- }
$$

